\title{
NANO-CHARACTERIZATION OF TYPE-G CEMENT SLURRY INCORPORATING NANOCLAY CURED UNDER HIGH TEMPERATURE AND PRESSURE
}

\author{
M. KALIMUR RAHMAN ${ }^{*}$, S. H. ABOUBAKR ${ }^{* *}$, M. M. REDA TAHA ${ }^{\dagger \dagger}$ \\ "King Fahd University of Petroleum and Minerals (KFUPM) \\ Dhahran, Saudi Arabia \\ e-mail: mkrahman@kfupm.edu.sa \\ ** University of New Mexico \\ Albuquerque, NM USA \\ e-mail: sherif@unm.edu \\ ${ }^{\dagger \dagger}$ University of New Mexico \\ Albuquerque, NM USA \\ e-mail: mrtaha@unm.edu
}

Key words: Nano-clay, Nanoindentation, Microstructure, Oil well cement

\begin{abstract}
Type-G cement slurry with various admixtures commonly used in oil/gas well cementing (OWC) incorporating 1,2 and 3\% nanoclay particles by weight of cement were produced. A water/cement ratio of 0.44 was used and the mixes were subjected to a temperature of $290^{\circ} \mathrm{F}$ and a pressure of 4666 psi for 48 hours. First, the effect of nanoclay on compressive strength evolution was investigated. Second elastic and viscoelastic characteristics of the cementitious mixes were characterized using nanoindentation. The nanoindentation tests enabled evaluating the maximum indentation depth, plastic depth, and the reduced elastic modulus. Furthermore, dwell time of 60 seconds was used to evaluate creep compliance of the cement mixes incorporating nanoclay. Fracture toughness was estimated from the nanoindentation data during the dwell loading period. Scanning electron microscope (SEM) and X-ray diffraction (XRD) microstructural analyses were conducted to explain the results observed using nanoindentation. Furthermore, finite element modeling was used to simulate the nanoindentation test and to extract the stress-strain Type-G cement material incorporating nanoclay and cured under high temperature and pressure. Moreover,
\end{abstract}

The experimental observations showed that nanoclay improved compressive strength evolution with time compared with neat cement and eliminated strength retrogression problem. Furthermore, using 1 and $2 \%$ nanoclay resulted in insignificant change $(-28$ to $+12 \%)$ of the reduced elastic modulus compared with neat cement. However, a high content of $3 \%$ nanoclay resulted in a significant increase of $(+54 \%)$ in the reduced elastic modulus and a significant reduction in creep compliance compared with neat cement. Fracture analysis of nanoindentation data showed a significant improvement of fracture toughness due to the addition of nanoclay. XRD analysis and SEM investigations proved that the incorporation of nanoclay in the cement mix transforms the Calcium Hydroxide $(\mathrm{CH})$ to calcium silicate hydrate $(\mathrm{C}-\mathrm{S}-\mathrm{H})$ and reduced capillary porosity leading to higher elastic modulus and reduced creep compliance compared with neat cement. Finally, the extracted stress-strain curves using the finite element method shows that adding nanoclay resulted in stiffening OWC paste. The significance of nanoclay seems strongly dependent on the nanoclay content and the quality of its mixing with cement. 


\section{INTRODUCTION}

Oil well cement (OWC) slurry is a suspension of cement, water and performance controlling chemicals, which is pumped down into the well and placed in the annular space between the well casing and the geological formations surrounding to the wellbore. The cement annulus is exposed to high temperature and high pressure (HTHP) and has to resist weak or porous formations, corrosive fluids, and over-pressured formations encountered, which can result in mechanical damage and ultimate failure of the cement sheath, potentially leading to microannulus. The oil well cement system should meet a wide range of short and long-term criteria to ensure robust production. This includes but not limited to limiting the amount of free water, controlling thickening time, limiting filtrate loss, and ensuring acceptable strength development. Furthermore, OWC shall have high resistance to chemical attacks and relatively high thermal stability and integrity against aggressive environments [1] The American Petroleum Institute (API) in API-10A [2] specified special types of OWC for deep borehole operations including Type $\mathrm{G}$ and Type $\mathrm{H}$ cements. Several additives such as fluid loss agent, defoamer, retarder, dispersants and friction reducer are also used in the cement mix. Silica flour in the range of $30 \%-40 \%$ is used to combat strength retrogression in cement sheath and to reduce permeability at high temperature and pressure conditions [3] in deep wells.

Nanomaterials have been suggested as a new class of materials capable of making significant changes in material characteristics and have shown great potential in several applications [4] Nanomaterials, having a particle size in the range of $1-100 \mathrm{~nm}$, are now being commercially available and have been used in several applications. However, the use of nanomaterials is relatively challenging because of their relatively very large surface area, which get them to be very reactive and tend to agglomerate unless well dispersed [5]. Nanosilica has been reported to have a great potential in improving cement slurry properties such as developing high early strength, controlling fluid loss [6, 7]. The use of nanomaterials in the oil and gas industry is still to be fully explored. Recent investigations have shown that Nanosilica not only tends to increase the compressive strength of cement, but also increases cement brittleness due to the increased silicate polymerization when cured under high temperature and pressure [8]. Nanoclay has been reported to increase stiffness and strength of cement materials, and decrease moisture absorption and permeability to gas and water [9]. There has also been research on using nanoclay to stiffen and limit creep of polymer composites [10].

In a typical Type-G neat cement subjected to high temperature and pressure conditions, the rate of compressive strength development is usually high and a relatively high initial compressive strength is achieved. However, the strength typically gets reduced with time as a result of relatively high temperature (in excess of $110^{\circ} \mathrm{C}$ ) due to formation of porous structure. This phenomenon is well-known in OWC and is known as strength retrogression. Nanomaterials have been suggested to overcome this issue. In this paper, cement slurry used for oil well operations of 14000 feet depth, with bottom hole circulating temperature of $228{ }^{\circ} \mathrm{F}$ and static temperature of $294^{\circ} \mathrm{F}$ with different percent of nanoclay $(0,1,2$ and 3$) \%$ in the cement mix, were investigated.

\section{EXPERIMENTAL METHODS}

\subsection{Materials}

Cement slurries used in this study are prepared using high sulfate-resistant API Class $G$ oil well cement. The oil well cement slurry mix used in the experimental program comprises API Class-G cement powder and nanoclay. The cement additives are added as weight percentage (wt. \%) of cement as presented in Table 1. 
Table 1: Mix proportions for cement slurry additive by wt.\% of cement.

\begin{tabular}{lc}
\hline Additive & wt. $\%$ \\
\hline Fluid loss additive & 0.70 \\
\hline Microsilica & 35.0 \\
\hline Cement retarder & 1.00 \\
\hline Cement friction reducer & 0.80 \\
\hline Expanding agent & 1.0 \\
\hline Anti-foaming agent & $1 \mathrm{pt}$. \\
\hline
\end{tabular}

The expected cement density was $125 \mathrm{pcf}$ and the water to cement ratio was kept at 0.44 .A number of admixtures and nanoclay were used in the slurry mix design. Nanoclay is composed essentially of silica, alumina, water, and lesser quantities of iron, magnesium, sodium and potassium. Nanoclay is a layered material with a thickness in the order of $10 \mathrm{~A}^{\circ}$ and with a width up to $1000 \mathrm{~nm}$ [11].

\subsection{Specimen preparation}

All neat cement specimens and specimens incorporating 1,2 , and $3 \%$ nanoclay were cured under high temperature and pressure conditions of $290^{\circ} \mathrm{F}$ and 4666 psi for 48 hours. The cured specimens are shown in Figure 1.

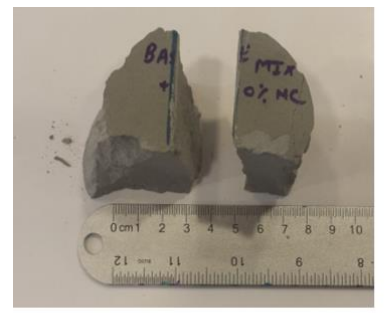

Neat

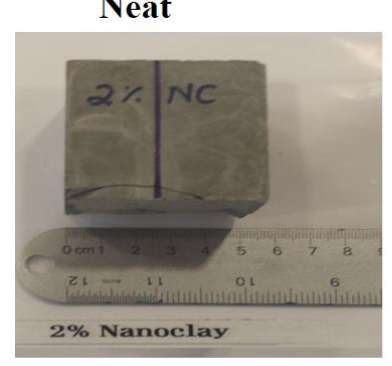

2.0 wt.\% Nanoclay

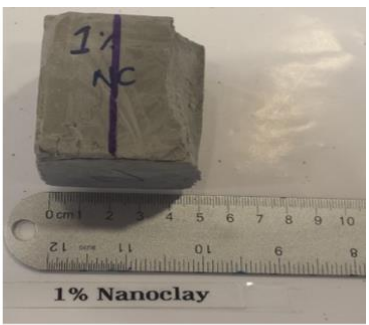

1.0 wt.\% Nanoclay

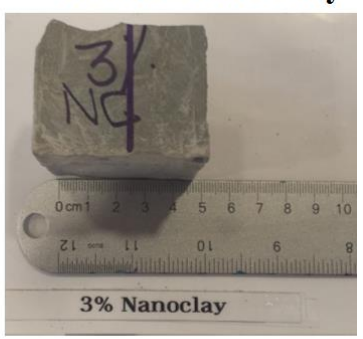

3.0 wt.\% Nanoclay
Figure 1: All cement specimens with and without nanoclay after curing at high temperature and pressure.

For all specimens, one intermediate part was harvested from the center of the specimen. The harvested specimens were then prepared for nanoindentation by casting them in fast-set acrylic to keep the specimens in place during polishing. The specimens were polished on a Buehler Ecomet 3 auto-polisher with a Buehler 2 power head. Water was used for lubrication for polishing. 125-micron, 70-micron, 30micron, 9-micron, and 1-micron diamond pad were used on sequences for $10,15,15,30$, and 60 minutes respectively. Specimens were sonicated for 2 minutes in water in between polishing. Polishing continued until a mirror like surface was obtained.

\subsection{Compressive strength evolution}

The compressive strength of cement system is an indicator of its integrity and stability against sustained long-term stresses. Pumping of cement efficiently, placing it safely on time, assuring cement integrity after placement, prior to resuming drilling operation, are critical issues to be considered. Therefore, compressive strength evolution within the first 48 hours is extremely important for field applications. Compressive strength evolution was measured using an ultrasonic cement analyzer (UCA) until set time. The compressive strength after set was determined using conventional compressive strength test. The evolution of compressive strength of the cement systems, including the neat cement, mixes with $1 \%, 2$ $\%, 3 \%$ nanoclay was measured using UCA under high temperature $\left(143{ }^{\circ} \mathrm{C}\right)$ and pressure (322 bars) for 48 hours.

\subsection{Nanoindentation test}

Depth-load hysteresis nanoindentation test was performed using NanoTestTM 600 indenter system from Micro Materials, Inc., Wrexham, UK shown. A $10 \mu \mathrm{m}$ diameter spherical indenter was used, with a loading and unloading rate if $0.0125 \mathrm{mN} / \mathrm{sec}$, initial load of $0.05 \mathrm{mN}$, maximum load of $0.6 \mathrm{mN}$, and the maximum load was held for dwell time of 60 sec. The Indentations were made on ten gridlines spaced $200 \mu \mathrm{m}$ apart; each gridline contained 10 indentations spaced at $100 \mu \mathrm{m}$. The spherical indenter tip covers a larger indentation area than Berkovich indenter at same indentation depth allowing for investigating the composite mechanical 
response at the nanoscale, while Berkovich indenter tip has pyramidal edges and leaves a much smaller indentation imprint so it is supposed to indent single-phase material [12].

The recorded load-indentation data was analyzed using the method outlined by Oliver and Pharr [13]. The reduced modulus $E_{r}$ is computed as

$$
\frac{d P}{d h}=2 E_{r} R_{r}{ }^{1 / 2} h_{e}^{1 / 2}
$$

where $d P / d h$ is the slope of the indentation load-depth curve at the start of unloading computed as the slope of a line tangent to the unloading curve as shown in Figure 2.

$R_{r}$ is curvature of the residual impression, and $h_{e}$ is elastic depth [14]. Tweedie and van Vliet [15] reported that creep compliance $J(t)$ under spherical indenter with a constant applied load can be computed as

$$
J(t)=\frac{8 \sqrt{R_{i}}}{3 P_{0}(1-v)}\left[h(t)^{\frac{3}{2}}\right]
$$

where $h(t)$ is nanoindentation depth as a function of time, $v$ is Poisson's ratio, $R_{i}$ is the indenter radius, and $P_{0}$ is the maximum applied indentation load.

Furthermore, the fracture toughness, i.e. critical energy release rate $G_{I C}$, of the OWC with and without nanoclay was evaluated using the constant loading stage during nanoindentation. Energy release rate $(G)$, defined as the energy available for an increment of crack extension, is used to quantify the rate of change of the potential energy of a cracked elastic solid as the crack grows [17], and is calculated as:

$G=-\frac{\partial U}{\partial A}$

where $U$ is the potential energy, and $A$ is the crack area. Here, a ficitious crack is assumed to grow during the constant loading stage. The energy dissipated during the constant loading stage is divided into two parts: a viscoelastic component due to creep and a cracking component responsable for extending the ficitious crack surface from position 1 to position 3 as shown in Figure 2.

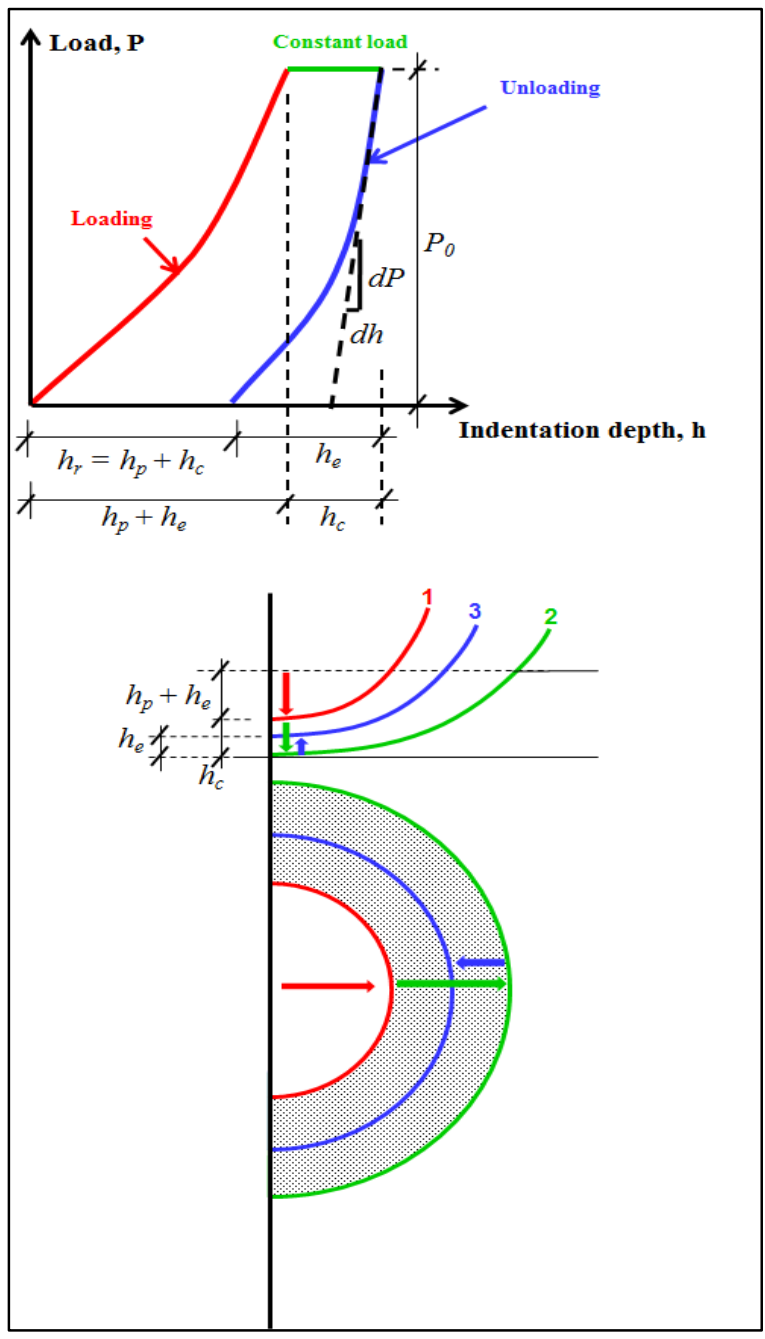

Figure 2-Geometry of load-depth change during different loading stages of nanoindentation used to calculate cracking energy and energy release rate.

The change in potential energy $\partial U$ was calculated by calculating the difference between strain energy within the constant loading stage, and energy dissipated by material viscoelasticity. Energy dissipated by viscoelasticity was calculated by establishing viscoelastic stress-strain curve using creep compliance calculated in equation (2). Crack surface area of the ficitious crack $\partial A$ was calculated as the difference between the surface area of spherical cap of indented surface at position 3 after applying the constant loading 
and that of position 1 before applying the constant loading.

\subsection{X-Ray diffraction}

X-ray diffraction (XRD) is a well-known methodology used to detect crystalline compounds. Considering a crystalline material has several repeating atomic planes, the angle between the emitted and diffracted X-ray beams are measured. When the $\mathrm{X}$-ray beams having a wavelength $\lambda$ is emitted to atomic planes of a material with an angle of incidence $\theta$, the beams are diffracted or transmitted according to the distance $d$ between the atomic planes, known as 'basal spacing', of the material [18].

The diffraction of the emitted beams occurs according to Bragg's law as

$n \lambda=2 d \sin \theta$

In this study, XRD is used to examine the microstructural composition of hydrated cement paste. Several compounds in hydrated cement paste such as alite $\left(\mathrm{C}_{3} \mathrm{~S}\right)$, belite $\left(\mathrm{C}_{2} \mathrm{~S}\right)$, ettringite (AFt), calcium hydroxide $(\mathrm{CH}$, portlandite) and calcium silicate hydrate (C-S$\mathrm{H}$, tobermolite) can be detected using the corresponding XRD patterns. The XRD peak locations for alite, belite, ettringite, portlandite and calcium silicate hydrate $(\mathrm{C}-\mathrm{S}-\mathrm{H})$ [19].

\subsection{Scanning electron microscope}

Microstructural analysis using scanning electron microscope (SEM) was conducted on fresh fractured cement specimens after being coated with gold. The scanning was conducted on a JOEL microscope under vacuum. The objective was to identify any significant difference of the microstructural features of the two materials.

\section{FINITE ELEMENT MODELING}

A finite element model was developed to simulate the nanoindentation of the cement paste with and without nanoclay. The objective of the modeling process is to extract the stressstrain constitutive model of the cement material with and without nanoclay. The method depended on simulating the OWC under nanoindentation using a bilinear stress-strain curve. Optimization methods were employed to identify the optimal bilinear stress-strain curve for each material that would enable the finite element model to give best fit to the experimental data. The stress-strain curves extracted can then be compared to identify the significance of nanoclay on OWC. To perform the above process efficiently, the dwell period representing the viscoelastic behavior of OWC with nanomaterials was excluded from the finite element modeling process. Material variables describing the stress-strain model include elastic modulus (E), yield stress (Y), and tangent modulus (T). In order to validate the predicted stress-strain curves, the loading and unloading curves for the FE models are compared with experimental tests using linear regression analyses of the force data. $A R^{2}$ value of 0.90 is defined as the minimum acceptable coefficient of determination. An example FE model is shown in Figure 3.

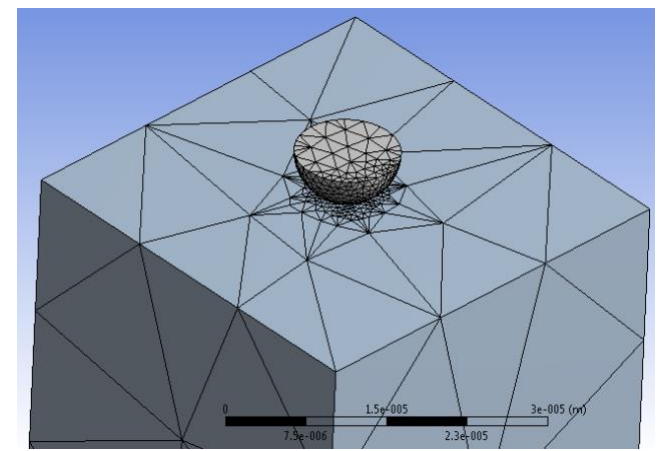

Figure 3-FE model of the spherical indenter tip and the cement paste specimen in nanoindentation.

\section{RESULTS AND DISCUSSION}

\subsection{Evolution of compressive strength}

The compressive strength of Type-G cement with and without nanoclay under high temperature and pressure conditions measured using UCA is presented in Figure 4. It can be observed that the compressive strength of cement mixes with nanoclay up to $3 \%$ nanoclay had a higher compressive strength evolution compared with neat cement. While neat cement showed some progress up to 12 hours of age, it declined afterwards as expected. Furthermore, 
the addition of nanoclay resulted in significantly higher compressive strength at 24 and 48 hours compared with neat cement mix. Cement paste with nanoclay did not observe any reduction in strength after 24 hours of age compared with neat cement.

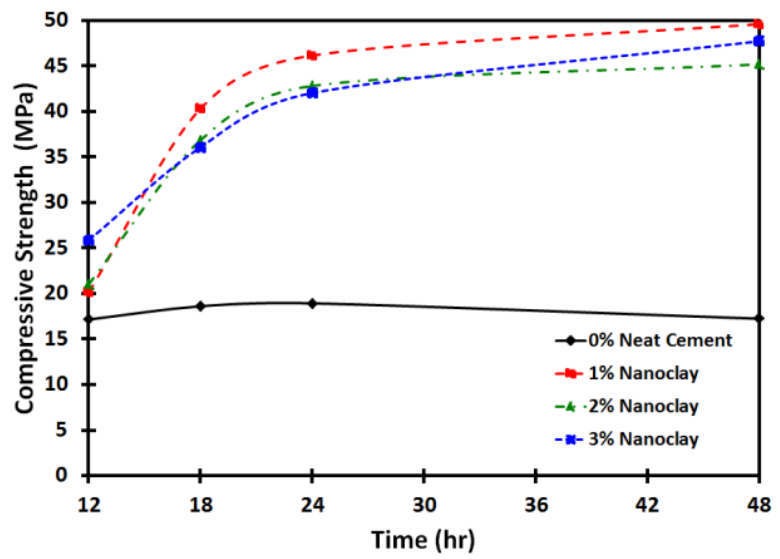

Figure 4: Compressive strength evolution with time for Type-G cement pastes with and without nanoclay and cured at high temperature and pressure.

\subsection{Nanoindentation}

Figure 5 shows the load-indentation depth of a median curve for the four mixes incorporating $0,1,2$, and $3 \%$ nanoclay. The horizontal line at the top of the curve represents the dwell period where creep was measured. The reduced modulus of OWC incorporating nanoclay was reduced for $1 \%$ nanoclay by $28 \%$ while for $2 \%$ and $3 \%$ nanoclay was increased by $12 \%$, and $54 \%$ respectively. Figure 6 shows the mean reduced modulus of each group. All comparisons are made with respect to the neat cement mix specimens.

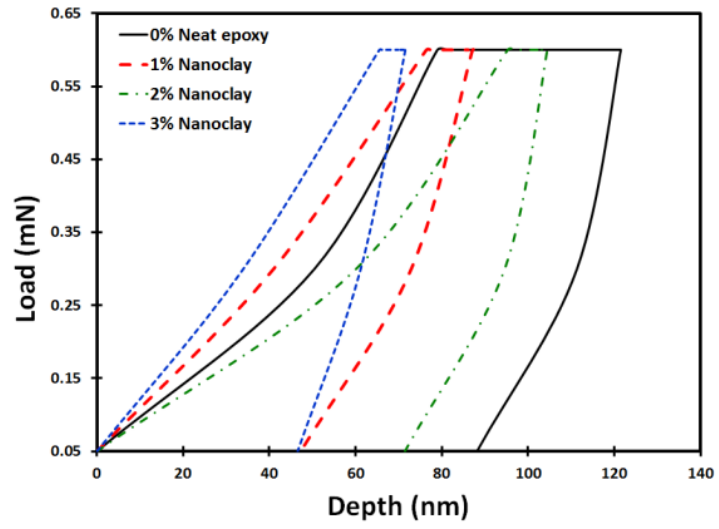

Figure 5: Median load-indentation depth of type-G cement pastes with and without nanoclay and cured at high temperature and pressure.

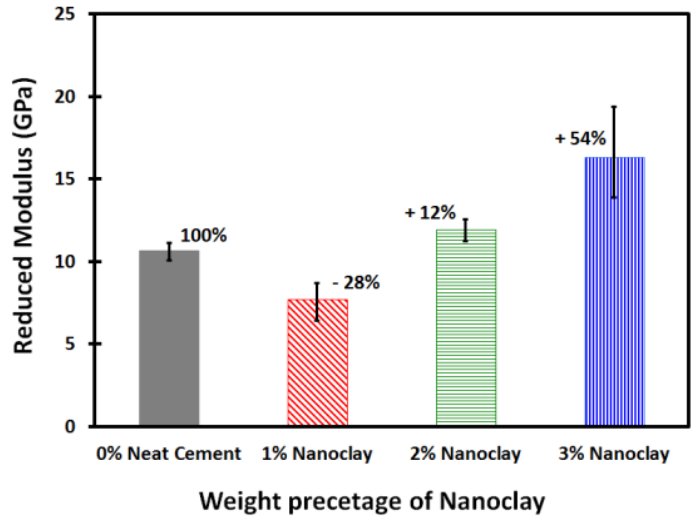

Figure 6: Reduced modulus of Type-G cement pastes with and without nanoclay and cured at high temperature and pressure.

The maximum indentation depth of OWC incorporating nanoclay was reduced for $2 \%$ and $3 \%$ nanoclay by $34 \%$ and $46 \%$ respectively. While for $1 \%$ nanoclay was increased by $35 \%$. Figure 7 shows the maximum depth for each group. All comparisons are made with respect to the $0 \%$ neat cement. The plastic indentation depth of OWC incorporating nanoclay was reduced for $2 \%$ and $3 \%$ nanoclay by $39 \%$ and $50 \%$ respectively. While for $1 \%$ nanoclay was increased by $35 \%$.

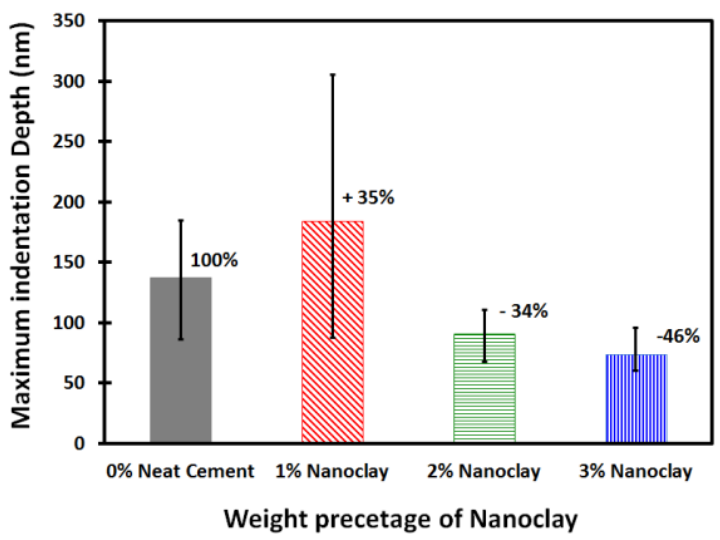

Figure 7: Maximum indentation depth of Type-G cement pastes with and without nanoclay and cured at high temperature and pressure .

Figure 8 shows the average normalized creep compliance curves extracted from nanoindentation analysis. It is obvious that creep of cement incorporating nanoclay depends on the nanoclay content significantly. While 1 and 2\% nanoclay showed the tendency to increase creep, $3 \%$ nanoclay tended to limit cement 
creep compared with neat cement material. Finally, Figure 9 shows the effect of nanoclay on fracture toughness $G_{I}$ of cement paste with and without nanoclay. It is apparent that the existence of nanoclay enabled increasing the fracture toughness significantly. The use of 3\% nanoclay allowed a considerable increase in fracture toughness of up to $140 \%$ compared with neat cement paste

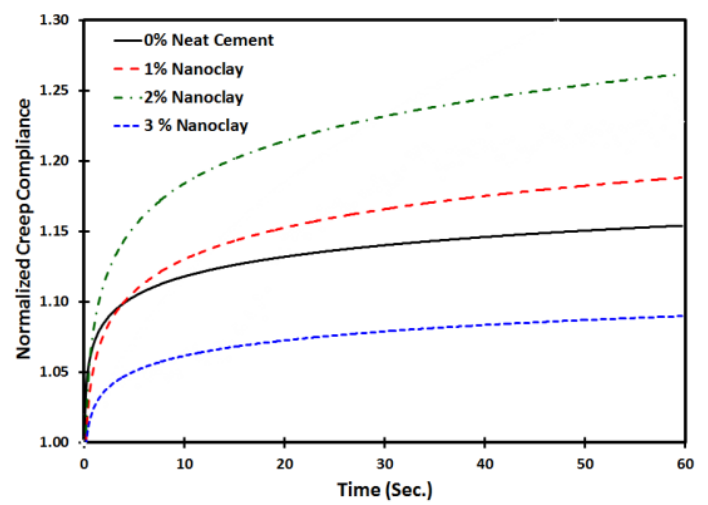

Figure 8: Mean normalized creep compliance of Type$\mathrm{G}$ cement pastes with and without nanoclay and cured at high temperature and pressure

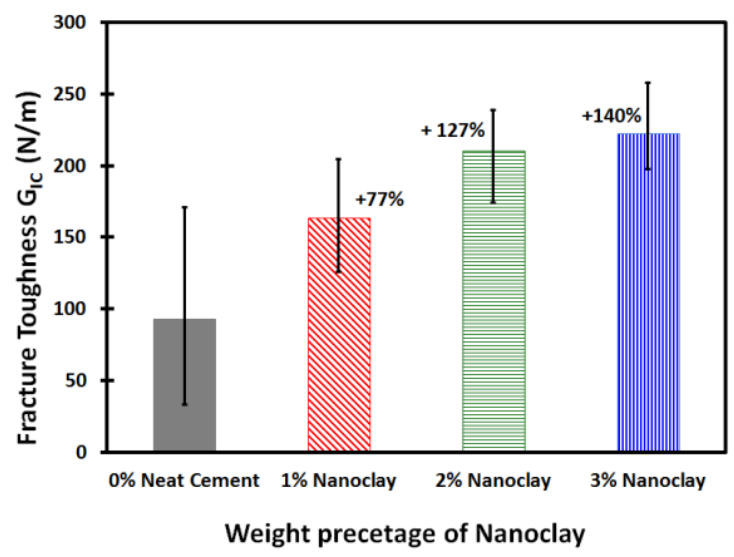

Figure 9: Fracture toughness (GIC) calculated for neat cement and cement pastes incorporating nanoclay cured at high temperature and pressure.

\subsection{Microstructural analysis}

The XRD chart of the neat type G-cement cured at high temperature and pressure is shown in Figure 10 and is compared to that of type $\mathrm{G}$ cement incorporating 3\% nanoclay and shown in Figure 11. While an obvious Portlandite $(\mathrm{CH})$ peaks can be observed in the XRD spectrograph of neat cement, no Portlandite peaks can be observed in Figure 10. Furthermore, some apparent quartz peaks appear in Figure 11. Those quartz peaks are related to a class of highly polymerized silicate chains that exist in nanoclay platelets. The absence of the Portlandite peaks confirms the ability of nanoclay with its rich silica content and high surface area to convert the weak $\mathrm{CH}$ crystals into stiff and strong C-S-H. This explains the additional stiffness and lower creep observed at high nanoclay content of $3 \%$. We trust the fluctuating results at low nanoclay content might be due to the limited amount of nanoclay making its significance limited.

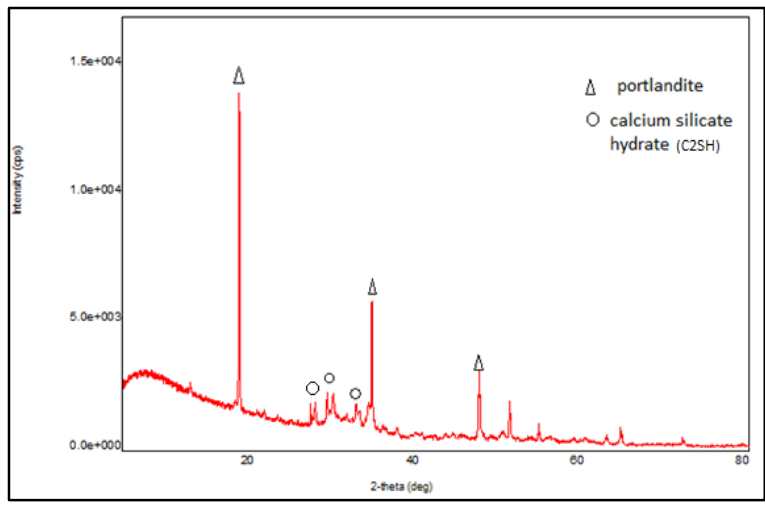

Figure 10: XRD of neat type $G$ cement cured at high temperature and pressure.

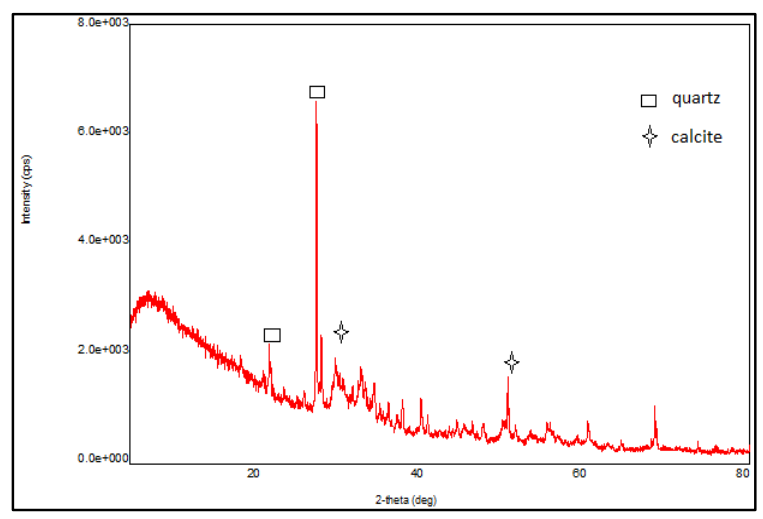

Figure 11: XRD of type G cement mixed with $3 \%$ nanoclay and cured at high temperature and pressure.

Furthermore, SEM micrographs of Type G cement incorporating nanoclay can be observed in Figures 12 and 13. While relatively large capillary pores can be observed in Figure 12, much smaller size pores can be observed in Figure 13 for cement incorporating 2\% nanoclay. 
We confirm that other nanoclay contents have similar microstructure observations. We limit the display of those micrographs for space limitations. Nevertheless, the microstructural analysis proves the ability of the nanoclay to alter the microstructure of type $G$ cement forming strong C-S-H and limiting the size of the capillary pores and thus improving cement stiffness and limiting creep as observed in nanoindentation tests.

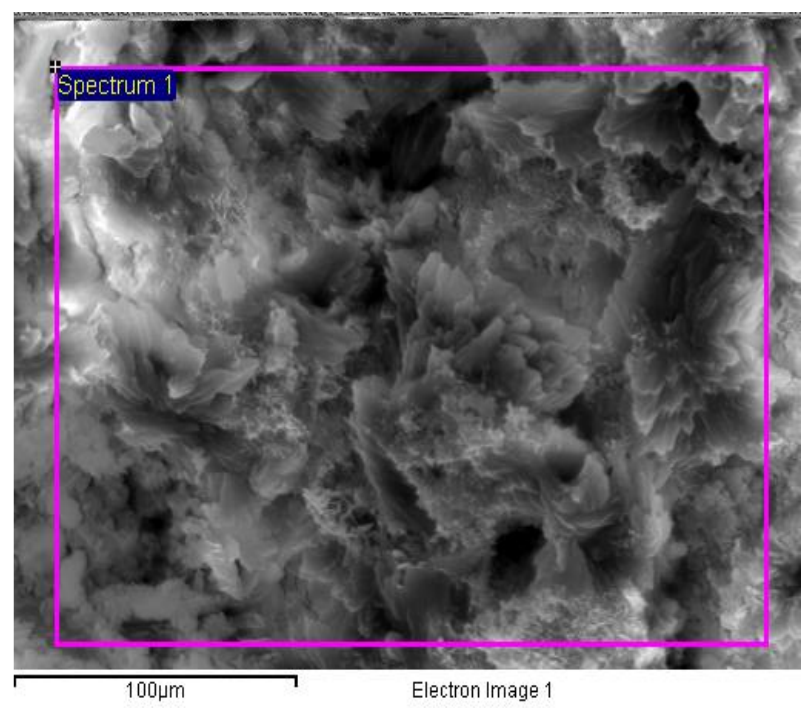

Figure 12: SEM micrograph of neat type $G$ cement cured at high temperature and pressure.

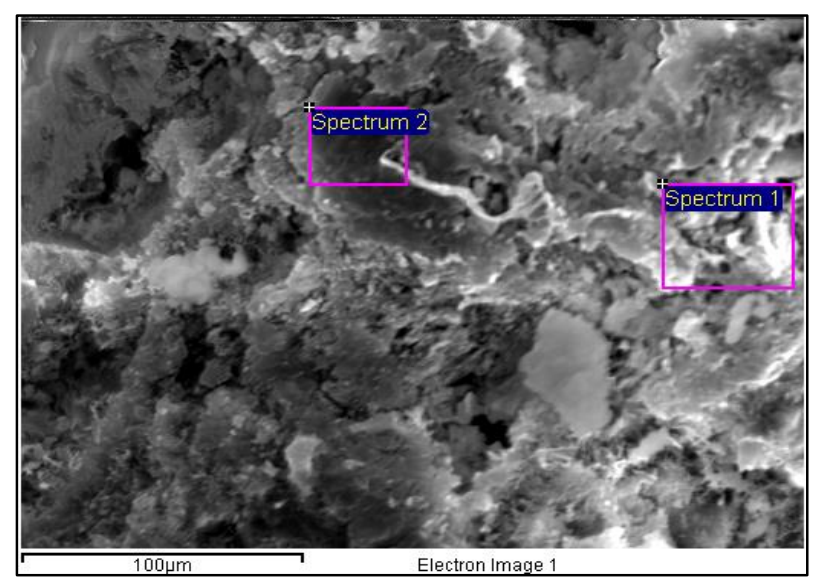

Figure 13: SEM micrographs of Type G cement mixed with $2 \%$ nanoclay and cured at high temperature and pressure.

\subsection{Finite element modeling}

An example simulation of the finite element model compared with load-indentation measurements is shown in Figure 14. A comparison of the extracted stress-strain can be observed in Figure 15. The extracted parameters of the stress-strain are presented in Table 3. It is obvious from Figure 13 that nanoclay results in significant stiffening of the OWC compared with neat cement materials. The result at $2 \%$ nanoclay seems at odd with the behavior of OWC incorporating 1 and 3\% nanoclay.

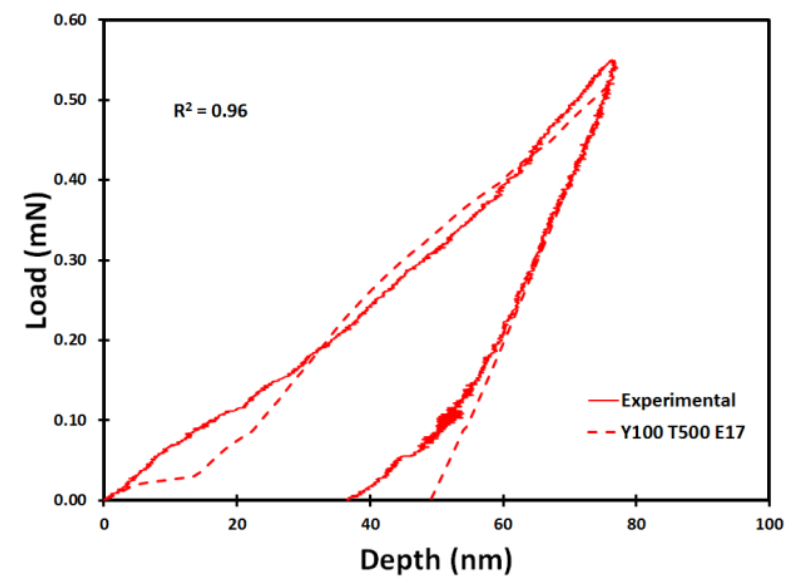

Figure 14: Normalized creep compliance as extracted from nanoindentation of neat cement, cement pastes nanoclay and cured at high temperature and pressure.

Table 3: Properties of OWC mixes with nanoclay as extracted from nanoindentation testing and FEA.

\begin{tabular}{cccc}
\hline Group & $\begin{array}{c}\text { Elastic } \\
\text { modulus } \\
(\mathrm{GPa})\end{array}$ & $\begin{array}{c}\text { Yield } \\
\text { strength } \\
(\mathrm{MPa})\end{array}$ & $\begin{array}{c}\text { Tangent } \\
\text { modulus } \\
(\mathrm{GPa})\end{array}$ \\
\hline 0\% Neat cement & 20 & 50 & 2.00 \\
\hline 1\% Nanoclay & 17 & 100 & 0.50 \\
\hline 2\% Nanoclay & 20 & 25 & 2.00 \\
\hline $3 \%$ Nanoclay & 22 & 100 & 1.00 \\
\hline
\end{tabular}

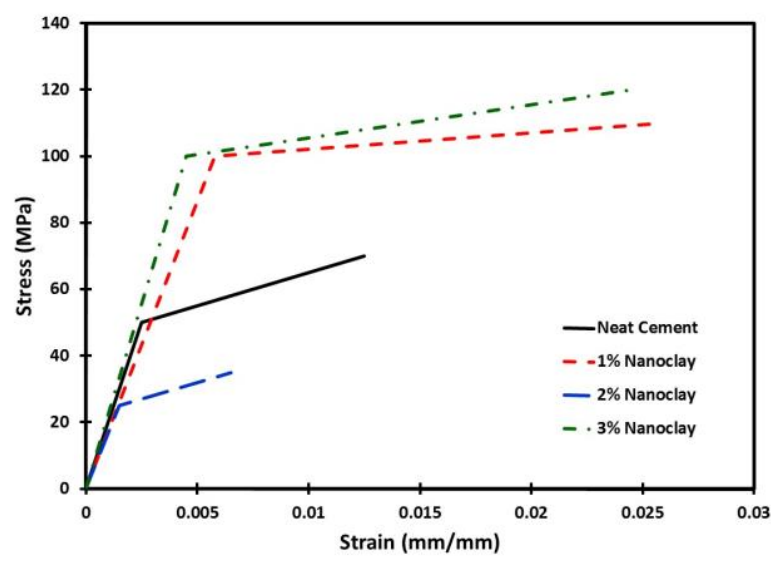

Figure 15: Normalized creep compliance as extracted from nanoindentation of neat cement paste and cement pastes incorporating nanoclay and cured at high temperature and pressure. 


\section{CONCLUSIONS}

Incorporating nanoclay with type $\mathrm{G}$ cement and curing the compounds at high temperature and pressure similar to that observed in deep boreholes, results in significantly changing OWC. Measurements using ultrasonic methods showed nanoclay to prevent the strength retrogression problem and produces cement paste that can maintain its compressive strength with time. Cement pastes incorporating nanoclay also showed favorable strength evolution with time that at a faster rate compared with neat Type-G cement. It is also evident that a relatively high content of nanoclay results in improving the cement microstructure by altering the weak Portlandite into calcium silicate hydrate and limiting the size of the capillary pores. This in its turn results in improving the elastic modulus of OWC and limiting its creep. It seems a relatively high content of nanoclay (higher than $2 \%$ ) might be required to ensure good mixing with cement and altering cement hydration. Finite element modeling of the cement paste with and without nanoclay was able to simulate the load-indentation curves observed in nanoindentation and was able to extract the stress-strain of OWC with and without nanoclay. The finite element model confirmed the above observations that adding nanoclay tends to stiffen the cement paste. A relatively high content of nanoclay is necessary to achieve such stiffening with good reliability.

\section{ACKNOWLEDGMENT}

This project was funded by the National Plan for Science, Technology and Innovation, King Abdulaziz City for Science and Technology (KACST) through the Science and Technology unit at King Fahd University of Petroleum and Minerals (KFUPM), Saudi Arabia award number \#09-NAN754-04. Help by Dr. Christina Salas from UNM in the finite element analysis is greatly acknowledged.

\section{REFERENCES}

[1] Ravi K, Bosma M, and Gastebled O (2002) Improve the Economics of Oil and Gas Wells by Reducing the Risk of Cement
Failure. Paper SPE 74497. DOI: 10.2118/74497-MS.

[2] American Petroleum Institute (2012) Specification for Materials and Testing for Well Cements API Spec. 10. American Petroleum Institute.

[3] Iverson B, Maxson J (2010) Strength retrogression in cements under hightemperature conditions. Thirty-Fifth Workshop on Geothermal Reservoir Engineering. SGP-TR-188.

[4] Singh S, Ahmed R (2010), Vital role of nanopolymers in drilling and stimulations fluid applications. doi: 10.2118/130413MS

[5] Praveen. S., Rana, S., Famgueiro, A Review on Nanomaterial dispersion, microstructure and mechanical properties of carbon nanotubes and nanofiber reinforced cementitious composites, Journal of Nanomaterials, 2013, paper ID 710175.

[6] Li, W., He, S. et al (2006), Investigations on the preparation and mechanical properties of the nano-alumina reinforced cement composite. Material Letters 60:356-359.

[7] Griffin, A., Kim, J., Rahman, M., and Reda Taha, M.M. "Microstructure of a Type G Oil Well Cement-Nanosilica Blend." Journal of Materials in Civil Engineering, Vol. 27, No. 5, 04014166. 2015

[8] Kim, J. J., Rahman, M.K., Abdulaziz, A.A., Al-Zahrani, M. and Reda Taha, M.M "Nanosilica Effects on Composition and Silicate Polymerization in Hardened Cement Paste Cured under High Temperature and Pressure", Cement and Concrete Composites, Vol. 43, 2013, pp. 78-85.

[9] Farzadnia, N., Ali, A. A. A., Demirboga, R., Anwar, M. P., Effect of halloysite nanoclay on mechanical properties, thermal behavior and microstructure of cement mortarts. Cement and concrete research, Vol. 48, 2013, pp. 97-104.

[10] Aboubakr, S.H., Kandil, U. F., and Reda Taha, M.M. "Creep of Epoxy-Clay Nanocomposite Adhesive at the FRP Interface: A Multi-scale Investigation", International Journal of Adhesion and 
Adhesive, Vol. 54, 2014, pp. 1-12

[11] Uddin F (2008) Clays, Nano-clays, and Montmorillonite Minerals. Met \& Mat Trans A 39A:2805-2814

[12] Vandamme, M., Ulm, F-J., Viscoelastic solutions for conical indentation, International Journal of Solids and Structures, vol. 43, pp. 3142-3165, 2006.

[13] Oliver, W. C., Pharr, G. M., "An improved technique for determining hardness and elastic modulus using load and displacement sensing indentation experiments" Journal of Materials Research, Vol. 7, pp. 1564-1583, 1992.

[14] Fischer-Cripps, A. C. Nanoindentation. Springer, 2nd edition, 2004

[15] Tweedie, C. A., and Vliet, K. J. V., "Contact creep compliance of viscoelastic materials via nanoindentation" Journal of materials research, vol. 21 , no. 6 , pp.15761589, 2006.

[16] Young, J.F., "Investigation of calcium silicate hydrate using silicon-29 nuclear magnetic resonance spectroscopy," Journal of the American Ceramic Society, vol. 31, no. 3, pp.C118-C120, 1988.

[17] Shah, S. P. Swartz, S. E., Ouyang, C., Fracture Mechanics of Concrete: Applications of Fracture Mechanics to Concrete, Rock and Other Quasi-Brittle Materials, John Wiley \& Sons, 1995.

[18] Taylor, H.F.W., "Cement Chemistry", Thomas Telford, 2nd edition 1997.

[19] Saoût GL, Le'colier E, Rivereau A, Zanni H. Chemical structure of cement aged at normal and elevated temperatures and pressures, Part I: Class G oilwell cement. Cem. and Conc. Res. 2006; 36:71-78. 